\title{
Influence of Game Theory on Physical Education Teaching Mode
}

\author{
Guoqing Sun \\ College of physical education, Shandong University of Finance and Economics, Jinan Shandong \\ 250014, China
}

Keywords: Game Theory, Physical Education, Teaching Mode, Influence, Exploration

\begin{abstract}
Under the influence of years of exam-oriented education in the past, physical education has been neglected by the school. Today, this situation has changed quietly with the gradual infiltration of curriculum reform and quality education. We put forward the application of game theory to implement management and teaching theory. Applying the game theory to PE teaching process is beneficial to improving teaching quality, improving students' interest in learning and their interest in sports activities, helping teachers to complete the teaching objectives and tasks of PE health course effectively, and providing reference for PE reform in colleges and universities.
\end{abstract}

\section{Introduction}

For a long time, physical education has always occupied a negligible position in the domestic education system. Physical education in colleges and universities is in name only. In recent years, the domestic higher education has gradually shifted toward the direction of popularization, and people are paying more attention to the physical education in colleges and universities. At present, each domestic university is in an enrollment area each year in an expansion. Therefore, colleges and universities must make a detailed analysis of the characteristics of college students to take appropriate teaching methods to carry out physical education. The main content of college PE teaching is to enhance the physique of college students, let them know and master sports knowledge and skills, and feel the sports team and the spirit of never give up, so as to then realize the comprehensive quality education to college students.

Game theory is a theory of conditioning theory that abstract, summarize and summarize people's behavior strategies in various incidents. These theories also involve all aspects of people's lives and become one of the theoretical bases of systems management science such as economic and military strategies in modern enterprises. Therefore, the game has great attention in all fields, but in the field of sports, although the invisible game is inevitable, the game for the field of sports is seldom discussed.

According to the basic concept of game theory, college sports teaching is generally both teachers and students as both sides of the game, both during the game during the game. The elements that exist during the period of physical education in colleges and universals are basically in line with the general concepts of game theory, so that the whole course of physical education in colleges and universities can be treated as a game between teachers and students. During this period, teachers can adopt various strategies and methods related to teaching to manage and evaluate students. In the whole course of the game, the strategies adopted by teachers can be started from the aspects of attendance, evaluation and management, in order to evaluate students' overall attitudes toward physical education. The whole game is the successful completion of the pre-planned teaching tasks, so that students get the physical aspects of exercise, understanding and mastery of the relevant sports skills, understands the sports have the meaning of the spirit level. Students in the process of this game can be happily relaxed, learn some of the correct skills of sports, sports-related hobbies. Thus, in the entire process of physical education teaching in universities, the teachers and students have achieved the game effectiveness. 


\section{The Proposed Methodology}

Game Theory in College Physical Education. During the entire game of physical education in colleges and universities, teachers and students who are both players in the game hope that each can get the most benefit from this process.

P1 is used to represent the salaries of the teacher during class, a1 is the emotional income of the teacher during class, b1 is the teacher's responsibility for teaching the input during this period, b2 is the period in which the teacher is not responsible for teaching the input Cost, $\mathrm{n} 1$ represents the outstanding achievement that the student earnestly exercises in the class, n2 represents the achievement that the student does not seriously exercise in the class, h1 represents that the student can not devote one's whole body and mind to the physical gain in the class, h2 represents the student class Serious physical exercise gains in the body, $\mathrm{m} 1$ on behalf of students can not seriously participate in the relevant costs of exercise, $\mathrm{m} 2$ on behalf of students to participate in training related to the serious cost. Where b1>b2, m2>m1, h2> h1, n1>n2.

To achieve equilibrium during this game, we must determine the size of p1 + a1-b1 and p1-b2, n1 $+\mathrm{h} 2-\mathrm{m} 2$ and $\mathrm{n} 2+\mathrm{h} 1-\mathrm{m} 1$. According to the actual situation, we can get $\mathrm{p} 1+\mathrm{a} 1-\mathrm{b} 1>\mathrm{p} 1-\mathrm{b} 2, \mathrm{n} 1+$ h2-m2>n2 + h1-m1. Therefore, in this game process, (serious, serious) is a balanced solution. This balanced solution represents that during the teaching period of physical education in colleges and universities, only the teachers should be responsible for the classes seriously, the students should exercise their skills carefully and master the relevant skills effectively so as to maximize the benefits of teachers and students during this game.

Game teaching methods. In the sports classroom, the game usually embodies the characteristics of comprehensiveness, entertainment, enlightenment and fun as well as the function of improving the health index. It can conceal the overall teaching goal of the university. Among the physical education in colleges and universities, taking the form of games as a starting point can help students to enhance their love of physical education curriculum, enable students to quickly integrate into the teaching and participate in the classroom atmosphere created by teachers. Every student who participates in physical education generally hopes to show his ability to gain recognition and respect from teachers and other students. The game is just a platform for students to show themselves. In the game, students can enjoy a pleasant confrontation, the game can help students show their physical strength, wisdom and skills in a natural form, and then you can experience the joy. This shows that the beginning of the game in the form of physical education, students can have the moral aspects of quality training. At the same time, students can also show their intelligence and other advantages, so that teachers can better understand the characteristics of students and conduct personalized teaching. However, during the game teaching in colleges and universities, we must follow the principles of education, exercise, safety and fun in order to ensure the smooth and orderly conduct of physical education.

During the teaching of $\mathrm{PE}$, college teachers can use the form of grouping to activate the classroom atmosphere, let the students give full play to the teamwork and the main role, and effectively stimulate the students' potential abilities. Teachers in the group teaching, we must avoid the formal adherence to the formal group, the former will not have the general characteristics of the group changes, from the students have the spiritual experience level reasonable grouping. During the game, group teaching is for teachers and students to achieve the highest benefits, the teaching goal is completed successfully. Therefore, the sports group teaching in colleges and universities must follow the elements of teaching materials, sports venues and sports equipment, according to the characteristics of students in detail, if the teacher during teaching regular grouping will hinder the teaching effectiveness. Divide into groups and teach and pay attention to the flexibility. Teachers and students should clarify their respective positions in teaching, try to correct their shortcomings, in order to achieve balanced game returns, and thus achieve their maximum benefits.

During the teaching of physical education, teachers must encourage students in many aspects so as to enhance their confidence in sports activities. For example, when teachers lead students to warm-up, teachers can encourage students from the aspects of language, such as "you are serious and your attitude is very standard". Another example is during the game, teachers can be given to the winning students appropriate material incentives for students to increase their determination to exercise. For 
students who do not perform well, teachers should not criticize them in front of many students. Instead, they should point out their mistakes and conduct demonstrations in person so that the students can correct them. In this way, the distance between the two sides of the game can be narrowed so as to enhance the emotional benefits of both parties and further enhance the overall revenue of both parties.

Physical education in colleges and universities is not merely to teach students the motor skills, but also must be thought, moral and other content of education. Therefore, during the teaching period, teachers must make students understand the relationship between employment and sports. Nowadays, many enterprises both at home and abroad attach great importance to sports activities. Enterprises often organize their internal employees to compete in sports. In the meantime, enterprises often choose talents with the same physical qualities when choosing candidates with the same qualifications. Therefore, students should not only have excellent professional skills, but also have good sports skills such as playing basketball, playing soccer and playing table tennis. This will help reduce the pressure on students during employment.

Game theory. Game Theory, also known as Games Theory, is a theory and method for studying the phenomena of struggle or competition. It is not only a new branch of modern mathematics but also an important discipline of operations research. Although game theory was formally proposed in recent years, the idea of game actually existed for a long time. The thought of game was contained in the ancient military writings of the "Art of War". After evolution and development, game theory has become a modern knowledge. Nobel Prize in economics in 1994 awarded three game theory as a symbol, game theory has become an important part of many disciplines. Game can be divided into: cooperative game, non-cooperative game, complete information incomplete game, static game, dynamic game. Elements of the game include: Bureaucrats, strategies, gains and losses, game outcomes, game equilibrium.

The ultimate goal of the game in the game is to profit, interest in different situations have different manifestations. The interests of the teaching field, from the reputation of the school's economic interests, to the benefits of teachers, and then to the training of students there are all forms of profit. From the perspective of constituent elements, game participants and game results are always present in life. It can be said that game is everywhere and ubiquitous, but the result of game changes because of the change of game rules. In teaching, the setting of the environment, the rules, will change the final result. Ho Yiu-hui's research verifies this point. It is believed that the system of rewards and punishment needs to be established in order to improve the current gaming environment in the state of interests game of all schools, parents and teachers in the reform of PE curriculum. The same holds true, Feng Bing, Liu Hang and others also believe that physical education curriculum reform requires a certain degree of reform environment, it needs to find a suitable living soil to develop themselves. This is the experience that the physical education curriculum reform came through after many years of exploration.

Reform and innovation, change is the rules and the environment, the concept has no doubt. This is not only theoretically supported macroscopically by the game theory, but also verified in the micro-environment of teaching. In PE teaching, the confrontation between sports and the essence of competition coincides with the game theory environment, which provides the soil for the use of game theory processing and analysis. Dai Ke's analysis of basketball lessons shows that applying the game theory can fully reflect the students' status as the main body of teaching and allow students to have appropriate choices for teaching contents. Targeted teaching can be conducted according to different positions of individuals. Students in the choice of the process, experience the fighting spirit, as well as the meaning of teamwork and competition, develop students' ability to adapt to society, teaching physical education as a function of humanistic education, assessment of evaluation from the evaluation of individuals to evaluation groups.

Game Analysis of Teaching Methods. In the game of physical education process, the focus of teachers and students, that is, the common utility value of both sides, carries out physical exercises for students, acquires sports awareness and cultivates interest in sports. However, the central point of the game is whether students accept physical training or not, At this time, how to get students to accept 
physical exercise has become the focus of teachers. In other words, raising the probability of students receiving sports training can increase the utility income of teachers and students at the same time.

In the process of physical education, teachers can use a variety of strategies to urge students to exercise, is the so-called teaching methods. Good teaching methods can make students feel happy in the learning process, enjoy the learning process, so that students have interest in learning, resulting in "I want to learn" to "I want to learn" change. The inappropriate teaching methods are often less effective. Past physical education, teachers use the traditional method to explain, model law, explain the model after letting students practice gourd ladle. In order to grasp the motor skills as soon as possible and to adopt repetitive practice method to let the students do a lot of repetitive training one by one, this will undoubtedly makes the students feel disgusted and reduce the probability of students receiving training. To give a simple example, many PE teachers adopt the method of "punishing the last one" in response to the student's late arrival problem, so that the students' mentality of "being late for themselves or not being accused of being accused by the law" will be "lately met Was severely punished, "students feel that if they choose to" late "this strategy will pay for themselves to raise the function, it will be scrambling to reach the classroom on time, but also will reduce the student resistance to teacher management methods.

Another teaching management method is called "even sitting." That is to say, the teacher stipulates a simple learning content that can be mastered or completed if the student learns it seriously. If there are students who cannot grasp or finish within the expected time, then the entire group will be then punished.

\section{Conclusion}

To sum up, game theory has a wide range of applications in production and daily life, but its potential value and effectiveness have not been valued by people at present. In the sports industry, the game theory is applied to practice. In the economic transition period of our country, through market-oriented, constantly exerting its own initiative, perfecting and innovating its profit model, changing the original interest pattern and making it develop more flexibility, and more to stimulate participants' initiative and enthusiasm. In the course of the game, participants and the entire project can be developed in them. Physical education in colleges and universities is not merely to teach students the motor skills, but also must be thought, moral and other content of education. Therefore, during the teaching period, teachers must make students understand the relationship between employment and sports. For the sports industry, the most direct benefit is the market profit, but in many competitions so that everyone's profit is maintained at a more balanced Nash equilibrium, to avoid the vicious competition in the industry, and make the use of game theory to regulate the market and management.

\section{References}

[1]. Aumann, R.J., 2017. Game theory. The New Palgrave Dictionary of Economics, pp.1-40.

[2]. Bi, C., Zhang, Q., Bao, R. and Wang, H., 2015, January. SAR image restoration and change detection based on game theory. In Intelligent Computing and Internet of Things (ICIT), 2014 International Conference on (pp. 55-58). IEEE.

[3]. Stöckelhuber, K.W., Wießner, S., Das, A. and Heinrich, G., 2017. Filler flocculation in polymers-a simplified model derived from thermodynamics and game theory. Soft matter, 13(20), pp.3701-3709.

[4]. Marden, J.R. and Shamma, J.S., 2015. Game theory and distributed control. In Handbook of game theory with economic applications (Vol. 4, pp. 861-899). Elsevier. 